\title{
Effects of Cell Phone Conversation on Visual and Auditory Reaction Time in Students of a Medical College in Bangalore
}

\author{
Nandini C. ${ }^{1}$, Roopashree K. ${ }^{2}$, Suparna Ghosh ${ }^{1}$ \\ ${ }^{1}$ Associate Professor, ${ }^{2}$ Assistant Professor, Department of Physiology, \\ East Point College of Medical Sciences and Research, Bidarahalli, Bangalore
}

\begin{abstract}
Background: In today's era cell phone usage has become so rampant and its being used while doing different task like driving, working in laboratory or office without realizing the distractions these cell phone can cause. People are not aware of the consequences these distractions can lead to \& also the harmful effects of electromagnetic radiations emitted by the cell phone.
\end{abstract}

Objective: To study the distracting property of cell phone use by assessing the visual reaction time in students of a medical college while conversing over the cell phone. To know the effect of long term use of mobile phone on visual and auditory reaction time based on history of no of hrs of phone usage per day. To find out gender difference in VRT \& ART .

Methodology: study population consist of 90 medical students, aged above 18yrs who were using mobile phones were selected randomly. After taking informed consent VRT \& ART was recorded using PC 1000 reaction time apparatus .student was allowed to converse on phone for 5 min during which VRT was recorded. After completing the conversation, once again ART \& VRT was recorded. Data was analyzed statistically using SPSS version 22.

Results and Conclusion: Mean VRT was significantly high during conversation when compared to conversation before. In comparison with gender, males have faster reaction time compared to females.

So we conclude that simultaneous use of cell phone causes distractions and reduces visual cognition performance leading to undesirable consequences. Dual tasking should be avoided and everyone should be educated to use mobile phone cautiously.

Keywords: ART (auditory reaction time), VRT (visual reaction time).

\section{Introduction}

Reaction time is a type of cognitive function test in which a stimulus is presented to elicit a response. The reaction time is the time from the onset of the stimulus to the beginning of the response. It is a measure of the

\section{Corresponding Author:}

\section{Dr. Roopashree K.}

Assistant Professor, Department of Physiology, East Point College of Medical Sciences and Research, Bidarahalli, Bangalore-49 latency between sensory perception of the stimulus by the nervous system and the effector motor response, including the neural processing. ${ }^{1}$ it has physiological significance and is a simple noninvasive test for central and peripheral nervous system. ${ }^{2}$ Slow reaction time can be dangerous while controlling moving machineries. Speedy reaction is helpful in sports such as football, basketball, tennis etc. It can be used as an index of cortical arousal which is an easy method. ${ }^{3}$

In present era mobile or cell phones have become an integral part of modern telecommunications in every individual life. In many countries, over half of the 
population uses mobile phones and the mobile phone market is growing rapidly. ${ }^{4}$

\section{Harmful effects of use of cell phones can be broadly put into 2 categories:}

1. Distractions caused by usage of cell phones, especially while focusing on task such as driving, working and in classrooms.

2. Effect of electromagnetic force emitted by these cell phones on biological systems. ${ }^{4}$

Mobile phones emit radio frequency energy, a form of non-ionizing electromagnetic radiation, which can be absorbed by tissues close to the phone. The amount of radio frequency energy a mobile phone user is exposed depend on many factors as the technology of the phone, the distance between the phone and the user, the extent and type of mobile phone use and the user's distance from cell phone towers. ${ }^{5}$ Some investigators have reported that exposure to cell-phone microwave fields can affect mental processes (or cognitive functions) as attention function, short-term memory tasks, information manipulation, or response-reaction times. ${ }^{6}$ Study conducted by national safety council have reported that, human brain doesn't perform multiple tasks at the same time. Rather, it handles the task sequentially by switching occurs between one task to other. At any one time only one task can be performed even when we are under the impression that we are doing two or more tasks simultaneously. Cognitive distraction prevents attention to visual scene which increases reaction time. ${ }^{7}$ A study conducted by Preece et al. had reported that exposure to microwave radiation from simulated cellular telephone transmissions affects cognitive function in humans in particular, a choice reaction time. Among 15 different cognitive function tests in randomized laboratory test sessions, subjects showed a significant microwave power-dependent decrease in reaction time (or an increase in speed) compared with the control subjects. ${ }^{8}$ At the same time study done by M Koivisto et al and N. Edelstyn results indicated that attention functions were differentially enhanced after exposure to the microwave fields emitted by mobile phones. ${ }^{9}$

Young people, especially teenagers nowadays are in the habit of multitasking while on the phone. More numbers of road traffic accidents are being reported because of mobile phone use during driving. It is very common to see the youngsters walking on road while typing on the smart phone with earphones in the ear unaware of the surroundings most of the time

There are lot of debates between those who believe that these cell phones are benign and those who believe that they are in fact dangerous, or at least potentially harmful. The primary research focus is on studying the distracting properties of cell phone use by recording visual reaction time while conversing over phone and to know the effect use of cell phone on cognition by recording visual and auditory reaction time before and after use of phone for $5 \mathrm{~min}$.

\section{Objectives:}

1. To study the distracting property of cell phone use by assessing the visual reaction time in students of a medical college while conversing over the cell phone.

2. To know the effect of long term use of mobile phone on visual and auditory reaction time based on history of no of hrs of phone usage per day.

3. To find out gender difference in VRT \& ART .

\section{Material and Method}

This was a cross sectional study conducted in $1^{\text {st }}$ year MBBS students in the Department of Physiology in a medical college in Bangalore. After getting approval from institutional ethical committee, students who volunteered were enrolled for the study. Ninety students of both male and females who are above 18 years and who are using mobile phones were selected randomly. Students having visual problems or color blindness, having injury or any defect in upper limbs, any neurological impairment, influence of alcohol, psychiatric illness or on psychotropic drugs were excluded from study.

After taking informed consent from the students, distant Vision was tested using Snellen's chart, near vision by jaeger's chart and color vision by Chart of Ischihara, Tuning fork test (Rinne's and weber test) were conducted to test the hearing capacity. History about number of hours of usage of phone per day was taken. Visual and auditory simple reaction time were measured using a reaction time apparatus PC 1000 Hertz's Reaction Timer which works on audacity software. ${ }^{10}$

Prior to testing, participants were given instructions. They were asked to observe the flashing of red light in the reaction time apparatus for visual reaction time and for auditory reaction time they were given ear phones in 
which they had to respond to sound stimulus. They were allowed to practice using dominant index finger. As light stimulus was given the subjects were instructed to react by pressing the button in reaction time apparatus. After recording visual reaction time, auditory reaction time was recorded by giving sound stimulus for which subjects were instructed to respond by pressing the button.

Initially baseline recording of auditory and visual reaction time was taken. Subjects were asked to converse over the phone for $5 \mathrm{~min}$ and while conversing visual reaction time was recorded. At the end of conversation once again visual and auditory reaction time was recorded using a reaction time apparatus which works on audacity software.

Data was analyzed using SPSS 22 version software. Categorical data was represented in the form of Frequencies and proportions. Continuous data represented as mean and standard deviation. Paired $t$ test was used as test of significance to identify the mean difference before and after the exposure. Pears on correlation was used to find the correlation between two quantitative and qualitative variables. $\mathrm{P}$ value $<0.05$ was considered as statistically significant after assuming all the rules of statistical tests

\section{Results}

Study was conducted in department of Physiology among ninety $1^{\text {st }}$ MBBS students, who are above 18 years and volunteered to participate in the study.

Table 1 shows the mean age and sex distribution of the subjects in the study. Mean age of the subjects was $19.04 \pm 1.005$ years. Out of 90 subjects 41 subjects were female and 49 were male.
Table 2 gives the mean VRT and ART in msecs comparing before, during and after conversation. In our study there was significant increase in Mean VRT during conversation compared to before conversation, but there was no significant difference in mean VRT after conversation in comparison with before conversation VRT.

There was no significant difference in mean ART after conversation in comparison with before conversation ART.

Table 3 shows Correlation between Number of Hours of usage with VRT and ART. In our study there was no significant correlation between Hours of use of phone with VRT and ART before, during and after conversation. Except for VRT during conversation, were in significant negative correlation was observed between Hours of mobile usage and VRT during conversation and vice versa.

Table 4 shows Mean VRT and ART in msecs comparison with respect to Hrs of phone use. There was no significant difference in mean VRT and ART between those who were using mobile phones $<6 \mathrm{hrs}$ and $>6 \mathrm{hr}$.

Table 5 shows the comparison of mean ART and VRT between males and females. In our study we found that there was significant difference in mean VRT between males and females. Mean VRT was high among females compared to males.

Similarly there was significant difference in mean ART between males and females. Mean ART was high among females compared to males.

Table 1: Age and Sex distribution of subjects in the study

\begin{tabular}{|l|l|c|c|}
\hline \multicolumn{2}{|l|}{} & Count & Percentage \\
\hline \multirow{4}{*}{ Age } & 18 & 27 & $30.0 \%$ \\
\cline { 2 - 4 } & 19 & 44 & $48.9 \%$ \\
\cline { 2 - 4 } & 20 & 11 & $12.2 \%$ \\
\cline { 2 - 4 } & 21 & 4 & $4.4 \%$ \\
\cline { 2 - 5 } & 22 & 4 & $4.4 \%$ \\
\hline
\end{tabular}




\begin{tabular}{|l|l|c|c|}
\hline \multicolumn{2}{|c|}{} & Count & Percentage \\
\hline \multirow{3}{*}{ Sex } & Mean Age & \multicolumn{2}{|c|}{$19.04 \pm 1.005$ years } \\
\hline \multirow{3}{*}{ BMI } & Female & 41 & $45.6 \%$ \\
\cline { 2 - 4 } & Male & 49 & $54.4 \%$ \\
\hline & Underweight & 11 & $12.2 \%$ \\
\cline { 2 - 4 } & Normal & 61 & \multicolumn{2}{|c|}{$67.8 \%$} \\
\cline { 2 - 4 } & Overweight & 16 & $2.2 \%$ \\
\cline { 2 - 4 } & Obese & 2 & $22.09 \pm 3.36$ \\
\hline
\end{tabular}

Table 2: Mean VRT and ART in msecs comparison before, during and after conversation

\begin{tabular}{|l|l|c|c|c|c|c|c|}
\hline & & Mean & SD & Median & Minimum & Maximum & P value \\
\hline \multirow{3}{*}{ VRT (milli sec) } & Before Conversation & 212.44 & 52.78 & 197 & 128 & 337 & 778 \\
\cline { 2 - 8 } & During Conversation & 412.26 & 121.50 & 372 & 221 & $<0.001 *$ \\
\cline { 2 - 8 } & After Conversation & 224.44 & 77.93 & 209 & 116 & 592 & 0.078 \\
\hline \multirow{2}{*}{ ART (milli sec) } & Before Conversation & 187.11 & 59.67 & 163 & 104 & 325 & \\
\cline { 2 - 8 } & After Conversation & 184.44 & 70.61 & 156 & 104 & 441 & 0.625 \\
\hline
\end{tabular}

Table 3: Correlation between Number of Hours of usage with VRT and ART

\begin{tabular}{|c|c|c|c|c|c|c|c|}
\hline \multicolumn{8}{|c|}{ Correlations } \\
\hline & & \multirow{2}{*}{$\begin{array}{c}\text { NO OF HRS } \\
\text { of phone } \\
\text { usage }\end{array}$} & \multicolumn{2}{|c|}{$\begin{array}{c}\text { Before } \\
\text { Conversation }\end{array}$} & \multirow{2}{*}{$\begin{array}{c}\text { At } \\
\text { Conversation }\end{array}$} & \multicolumn{2}{|c|}{ After Conversation } \\
\hline & & & VRT & ART & & VRT (milli sec) & ART (milli sec) \\
\hline \multirow{3}{*}{$\begin{array}{l}\text { NO OF HRS of } \\
\text { phone usage }\end{array}$} & Pearson Correlation & 1 & 0.066 & -0.026 & $-0.215^{*}$ & -0.099 & -0.152 \\
\hline & $\mathrm{P}$ value & & 0.536 & 0.808 & $0.042 *$ & 0.354 & 0.153 \\
\hline & $\mathrm{N}$ & 90 & 90 & 90 & 90 & 90 & 90 \\
\hline
\end{tabular}

Table 4:Mean VRT and ART in msecs comparison with respect to Hrs of phone use

\begin{tabular}{|c|c|c|c|c|c|c|}
\hline & & \multicolumn{4}{|c|}{ Hrs of Phone use } & \multirow{3}{*}{ P value } \\
\hline & & \multicolumn{2}{|c|}{$<6 \mathrm{hrs}$} & \multicolumn{2}{|c|}{$>6 \mathrm{hrs}$} & \\
\hline & & Mean & SD & Mean & SD & \\
\hline VRT & Baseline recording & 206.56 & 50.01 & 222.00 & 58.32 & 0.123 \\
\hline ART & Baseline recording & 182.44 & 57.78 & 205.78 & 65.05 & 0.479 \\
\hline
\end{tabular}

Table 5: Mean VRT and ART in msecs comparison with respect to Gender

\begin{tabular}{|c|c|c|c|c|c|c|}
\hline & & \multicolumn{4}{|c|}{ Gender } & \multirow{3}{*}{ P value } \\
\hline & & \multicolumn{2}{|c|}{ Female } & \multicolumn{2}{|c|}{ Male } & \\
\hline & & Mean & SD & Mean & SD & \\
\hline VRT & Baseline recording & 238.66 & 50.30 & 190.51 & 44.48 & $<0.001^{*}$ \\
\hline ART & Baseline recording & 205.39 & 62.00 & 171.82 & 53.60 & $0.007 *$ \\
\hline
\end{tabular}




\section{Discussion}

Reaction time is a cognitive function test which measures the latency between sensory perception and effector motor response. It's a simple test which helps us to analyze the sensory motor association. In present era, mobile phones have become an integral part of communication in every individual life. Apart from the harmful effects caused by the electromagnetic radiations emitted from these cell phones, the distractions caused by using cell phones while doing other task such as driving, operating heavy machinery in the laboratories are leading to lot of untoward incidences in our day to day life. This may be due to fact proven that our brain cannot concentrate on multiple task at a time and it handles the task sequentially by switching between one task to other. There are many studies which have proven that exposure to cell-phone microwave fields can affect mental processes (or cognitive functions) such as attention function, short-term memory tasks, information manipulation, or response-reaction times. ${ }^{6}$ So present study was done to assess \& compare the visual reaction time before and during conversation, To know the effect of long term use of cell phone on visual and auditory reaction time and also gender differences in VRT \& ART.

Cross-sectional study was done among 90 medical students, aged around 19 years who volunteered to participate in the study. After collecting the data, was analyzedusing SPSS 22 version software. Analysis of our study concludes that ART is faster than VRT, which supports existing studies done by authors like Pain \& Hibbs, Thomson et al. ${ }^{11,12}$ As Auditory signals reach cortex faster than visual signals ART is faster than VRT.

There was significant increase in visual reaction time while having a conversation over the phone compared to the VRT before conversation which confirms that use of cell phone can cause distractions while performing another task. This outcome of our analysis is supported by the study done by national safety council who has reported that, human brain doesn't perform multiple tasks at the same time. At any time only one task can be performed even though we assume that we are doing two or more tasks simultaneousl. ${ }^{7}$ Also study done by Preecee et al has reported that exposure to microwave radiation from simulated cellular telephone transmissions affect cognitive function in humans in particular choice reaction time. ${ }^{8}$ In contrary to our study, study done by M Koivisto et al and N. Edelstyn examined the relationship and reported facilitating effect between cognition and cell-phone exposure. ${ }^{1}$ There was no significant difference in mean VRT after conversation in comparison with conversation before and also there was no significant difference in mean ART after conversation in comparison with conversation before.

On comparison of mean ART \& VRT between males and females in our study there was significant difference in mean VRT between males and females. Mean VRT was high among females compared to males. Similarly, there was significant difference in mean ART between males and females. Mean ART was high among females compared to males. Study done by misra et al, Shelton kumar et al have also got similar findings that males have faster reaction time compared to females. ${ }^{13,14}$ This could be possible because of faster motor responses in males compared to females according to study done by silverman IW. ${ }^{15}$

In comparison with respect to no of hrs of usage of phone per day there was no significant difference in mean VRT and ART between those who were using mobile phones $<6$ hrs and $>6$ hrs.

\section{Conclusion}

Mobile phones are highly misused in today's era. Having seen the increase in visual reaction time during conversation, we can say that simultaneous use of cell phone causes distractions and reduces visual cognition performance leading to undesirable consequences. So dual tasking should be avoided and everyone should be educated to use mobile phone cautiously.

Limitation of the Study: Only visual and auditory reaction time was assessed. Other cognitive function test can also be used in future.

Acknowledgement: I Would like to acknowledge Dr Maruthi K N for developing the reaction time apparatus, the staff at the Department of Physiology for their help in arrangements and to the participants.

\section{Source of Funding: Self}

\section{Conflict of Interest: Nil}

\section{References}

1. Koivisto, M, A.Revonsvo, C. Krause, C. Haarola, L. Sillanmaki, M. Laine and H. Hamalainen, Effects of $902 \mathrm{MHz}$ electromagnetic fields emitted 
by cellular telephones on response times in humans. Neuroreport. 2000; vol. 11: page no. 413-415.

2. Nandini C, Hemashankar C and B C Vastrad. Comparative study of visual reaction time in congenital deaf and normal children. Biomedicine .2014; 34(4): 510-513.

3. Shinde P C, P A Pazare. Effect of Distraction on Choice Reaction Time in Normal Females and Males. World journal of Pharmaceutical Research 2013; 2 : 345-354.

4. The Effects of Cell Phone Usage on the Reaction Time of Humans . National Undergraduate Research Clearinghouse, 12. Available online at http://www. webclearinghouse.net/volume/. Retrieved August 16, 2018 .

5. Zahid Naeem. Health risks associated with mobile phones use. International Journal of Health Sciences, Qassim University Oct-Dec 2014; Vol. 8: No. 4

6. James C. Lin .Mental Process in Humans and Exposure to Cell-Phone Radiation, health effects. . IEEE microwave magazine Dec 2004.

7. National Safety Council. Understanding the distracted brain. White Paper March 2010. Available at distracteddriving.nsc.org. Accessed on $27^{\text {th }}$ March 2014.

8. Preece, G. Iwi, A. Davies-Smith, K. Wesnes, S. Butler, E. Lim and A. Varey. Effect of a $915 \mathrm{MHz}$ simulated mobile phone signal on cognitive function in man.Int. J. Radiat. Biol 1999; vol. 75: pp. 447-456,

9. Balasubramanium $\mathrm{M}$ et al. Effect of dual tasking on visual and auditory simple reaction time.

10. Archana P. Kumar, K. Mahesh Kumar1*, R. Padmavathi1, K. N. Maruthy and Sundareswaran. Validation of PC $1000 \mathrm{~Hz}$ Reaction Timer with Biopac ${ }^{\circledR}$ MP 36 for Recording Simple Reaction Time. Indian jurnal of physiology \& pharmacology 2019;63(2): 138-144.

11. Pain MT, Hibbs A. Sprint starts and the minimum auditory reaction time. J Sports Sci. 2007;25:79-86.

12. Thompson PD, Colebatch JG, Brown P, Rothwell JC, Day BL, Obeso JA, et al. Voluntary stimulussensitive jerks and jumps mimicking myoclonus or pathological startle syndromes. Mov Disord. 1992;7:257-62.

13. Misra N, Mahajan KK, Maini BK. Comparative study of visual and auditory reaction time of hands and feet in males and females. Indian J Physiol Pharmacol. 1985;29:213-8.

14. Shelton J, Kumar GP. Comparison between auditory and visual simple reaction times. Neurosci Med. 2010;1:30-2.

15. Silverman IW. Sex differences in simple visual re-action time: A historical meta-analysis (Sports Events) Sex Roles. 2006;54:57-69. 